\title{
Smiling in the rain: Seven reasons to be positive about uncertainty in hydrological modelling
}

\author{
John M. Juston, ${ }^{1 *}$ \\ Anna Kauffeldt, ${ }^{2}$ \\ Beatriz Quesada Montano, 2,3 \\ Jan Seibert, ${ }^{4,2,5}$ \\ Keith J. Beven ${ }^{6,2,7}$ and \\ Ida K. Westerberg ${ }^{2,8}$ \\ ${ }^{1}$ KTH Royal Institute of Technology, \\ Department of Land and Water \\ Resources Engineering, Stockholm, \\ Sweden \\ ${ }^{2}$ Uppsala University, Department of \\ Earth Sciences, Uppsala, Sweden \\ ${ }^{3}$ University of Costa Rica, Centre for \\ Geophysical Research, San José, Costa \\ Rica \\ ${ }^{4}$ University of Zurich, Department of \\ Geography, Zurich, Switzerland \\ ${ }^{5}$ Stockholm University, Department of \\ Physical Geography and Quaternary \\ Geology, Stockholm, Sweden \\ ${ }^{6}$ Lancaster University, Lancaster \\ Environment Centre, Lancaster, UK \\ ${ }^{7}$ ECHO, EPFL, Lausanne, Switzerland \\ ${ }^{8}$ IVL Swedish Environmental Research \\ Institute, Stockholm, Sweden
}

\section{*Correspondence to:}

John M. Juston, KTH Royal Institute of

Technology, Department of Land and

Water Resources Engineering, Stockholm,

Sweden

E-mail: juston@kth.se

Received 9 October 2012

Accepted 12 October 2012
This commentary is dedicated to the memory of Lars-Christer Lundin (1956-2012), Professor of Hydrology at Uppsala University, who was an inspiration in being positive as a researcher and in seeing opportunities rather than difficulties in the analysis and management of catchments.

\section{Introduction}

Over 20 years ago, the notion of 'positive uncertainty' was introduced in the field of psychology (Gelatt, 1989). This was coincident to some developments in the hydrological sciences (e.g. Beven and Binley, 1992; Grayson et al., 1992) which laid the foundation for today's continued efforts to explicitly acknowledge and quantify uncertainties inherent in our modelling efforts. 'Positive uncertainty' urges moving beyond deterministic frameworks of the past, but doing so not just by regrettably accepting that uncertainties are inevitable, but by positively thriving in the new perspectives that accompany this recognition (Gelatt, 1989). During a recent small workshop in Sweden while the rain was pouring down - we discussed some of the positive developments in recent years that have resulted directly from explicit recognitions of uncertainty in hydrological modelling. With the earlier paper of Pappenberger and Beven (2006) in mind, we here summarise that workshop and elaborate seven reasons to be positive about uncertainty in hydrological modelling.

How have the hydrological sciences benefitted in the last 20 years from the increased recognition of uncertainties, particularly in the modelling of time series data? In our view, uncertainty estimation is a means to address hydrologic research questions in an honest and robust way. There have also been (and will continue to be) new research questions and opportunities initiated by the recognition of what needs to be done to quantify and then constrain uncertainties. This notion fits intrinsically with the view of modelling as a learning process (Box, 1976), learning about the nature of the uncertainties involved and the possibility of reducing them by improving our models or our data.

\section{Seven Reasons to be Positive About Uncertainty Estimation}

()) We learn about data

Recent advances in quantifying uncertainties in modelling hydrological time series have led to a renewed scrutiny of the characteristics of the source data used for model input and calibration. Hydrology is a subject that, despite its importance to human well-being, suffers from significant measurement limitations (Klemeš, 1986; Beven, 2002; Sivapalan et al., 2003; Kirchner, 2006). Field and remotely sensed data are subject to random and systematic errors whose characteristics may vary over time, and the spatial and temporal commensurability (i.e. representativeness) of 
observations with modelled fluxes and storages is often an issue. Even the most basic of hydrological variables, such as rainfall and discharge, can be subject to significant uncertainties and inconsistencies (Viney and Bates, 2004; Stephens and Kummerow, 2007; Westerberg et al., 2010; Hamilton and Moore, 2012; McMillan et al., 2012).

These uncertainties impact our possibilities to derive inferences about hydrological processes and model representations (e.g. Brath et al., 2004; Krueger et al., 2010; Beven et al., 2011). The information content of a hydrological dataset for model calibration depends on when, how, and where these data were observed. For example, a number of recent modelling studies have shown that periodically sampled subsets of daily time series data can contain much of the information needed to calibrate a model (Vrugt et al., 2002; Juston et al., 2009; Seibert and Beven, 2009; Konz and Seibert, 2010). This means that the reliability of model predictions in ungauged areas can be significantly increased by taking a few new measurements, but further research is needed to provide guidance on how such measurements should be made to optimise the information gain. In some cases, additional data might not contribute to the improvement of model performance, as in the study by Lerat $e t$ al. (2012) when they tested adding flow data from nested subcatchments in the calibration of a rainfall-runoff model. Observational uncertainties can lead to combinations of model input and output data that are physically inconsistent or 'disinformative', and lead to incorrect inference (Beven and Westerberg, 2011). On the other hand, apparent outliers in the model residuals during periods of consistent and informative data might be the most revealing in testing model-structural hypotheses. This suggests that we should be both positive and proactive about finding ways of evaluating the information content of calibration data independent of any particular model structure (e.g. Beven et al., 2011).

McMillan et al. (2012) recently initiated a characterisation and catalogue of observational uncertainties, employing information from dozens of previous studies of precipitation, discharge, and water quality data. There are also now a growing number of examples where estimation of uncertainty in the model evaluation data is considered directly in model calibration (e.g. Thyer et al., 2009; McMillan et al., 2010; Westerberg et al., 2011). The increased attention given to uncertainties in the observational data and their role in hydrological inference, as manifested in the recent literature, is a positive development. It exemplifies Gelatt's concept of 'positive uncertainty' - recognising the inherent limitations and uncertainties in data make their use in hydrological modelling more complex, but it increases our possibilities to draw robust conclusions about present and future hydrological behaviour.

\section{(-) We learn about models}

We often use models as hypotheses about catchment responses to be tested. While we obviously want to be right for the right reasons, we also want to avoid being wrong for the wrong reasons. Paradoxically, a model that fails to represent our data may give the most positive outcome for our learning. In analysing the error signal and the behaviour of the model residuals, we can learn about the model-structural representation of the hydrological processes (Reusser and Zehe, 2011), but also about the effect of observational uncertainties on the inference (Krueger et al., 2010; Westerberg et al., 2011). We learn less from models that do not fail, only that they are still feasible hypotheses and can be used with some degree of confidence in prediction. Models that are successful in continuing evaluations will increase that confidence (though not necessarily multiplicatively when a new evaluation does not test a wider range of predictions than already evaluated, see Chatfield, 1995; Beven et al., 2008). In the case of models that fail, however, we will need to look for improvements to either the model concepts or the data (e.g. Fenicia et al., 2008). Then we may be able to improve the science.

The choice of the evaluation criteria against which we compare the simulated and observed catchment response is central for how much we can learn. A positive development in this area is the recent emphasis on accounting for uncertainties in evaluating how well models can match relevant information about the catchment response behaviour, extracted from the data (Yadav et al., 2007; Blazkova and Beven, 2009; Bulygina et al., 2009), but also from 'soft information' (Seibert and McDonnell, 2002; Winsemius et al., 2009). Focusing on the functional behaviour of catchments might also improve our opportunities to constrain predictive uncertainty in ungauged basins and for future changes in climate (Singh et al., 2011; Wagener and Montanari, 2011).

\section{(-) We produce more reliable and robust predictions}

Obviously, the modeller is more likely to be right if prediction bounds that specify the modelled uncertainty are provided rather than single values. While very wide prediction bounds might imply that a prediction is not very helpful to the decision maker, the important advantage of bounds is that the prediction uncertainty is openly communicated (even if there may still be issues about communicating the assumptions on which the analysis is based, see Beven, 2012). Considering a large number of possible parameter sets also makes results more robust to epistemic error. When considering only one 'best' parameter set, results might be overconstrained by the choice of this single parameter set, even if the predictions include estimation of uncertainty. This is because the choice of a 'best' model will depend on the particular realisation of epistemic error 
in the calibration data set. Such effects can be mitigated when results are based on a large number of parameter sets that will be more likely to give good results in prediction when the realisation of epistemic error might be different. Seibert and McDonnell (2010), for instance, used a model approach to detect land-cover effects on peak flows. They found that results could vary greatly between different parameter sets, indicating both the existence and lack of detectable changes, and robust results could only be achieved by the consideration of many parameter sets.

\section{(). We learn about the value of additional data}

Only if prediction uncertainties are quantified is it possible to consider the feasibility of reducing those uncertainties by using better (more informative) data, different types of data, or different model structures as part of the learning process. While again stressing the importance of a prior evaluation of the information content of data independent of any particular model structure, different types of data may be valuable in constraining the range of predictive models and consequent uncertainty bounds. Several studies have used uncertainty analysis to demonstrate the value of additional data such as groundwater levels (e.g. Seibert, 2000; Fenicia et al., 2008; Juston et al., 2009) and conservative tracers (e.g. Birkel et al., 2010) to constrain model simulations by providing information on internal state variables. Brunner et al. (2012) discuss the value of different types of observational data for the reduction of the predictive uncertainty of a 1-D vadose zone model. Other studies have suggested how a small amount of data of a different type was more useful to constrain uncertainties than a continuation of time series data of the same type (e.g. Juston et al., 2010). Studies such as these suggest positive ways that modelling with uncertainty analysis can feedback towards more efficient and focused data collection activities in the field.

\section{() We can engender trust by recognising and communicating uncertainties}

It is a common view amongst scientists that the public and policy makers need, and want, certain (deterministic) predictions (e.g. Frewer et al., 2003). However, communicating uncertainties and limitations of scientific knowledge can have a significant importance in gaining and retaining the trust of the public and decision makers. Failing to openly admit the limitations of knowledge can cause severe distrust in both science and regulatory institutions as, for example, in the case of the BSE crisis (e.g. Jacob and Hellström, 2000). Hence, scientists have much to gain from better risk communication. As Wardekker et al. (2008) say concerning communication of uncertainties: 'it is a matter of good scientific practice, accountability and openness towards the general public'.
The recognition of the need for communication of uncertainties is not just a top-down process. The Luteijn Commission, which was designated to evaluate the calamity polders (i.e., emergency flood storage areas) proposed as a spatial flood protection measure in the Netherlands, to involve the local stakeholders and to openly discuss uncertainties and assumptions, failed at accomplishing these tasks. This failure led to massive protests in Ooijpolder (one of the areas suggested for controlled flooding). The protesters, through the use of counter-experts, could successfully show that the knowledge base for the calamity polders was not sound and the plans were abandoned (Roth and Warner, 2007).

If it is important to be realistic about prediction uncertainties in decision making, an interesting issue arises when the uncertainties cover a very wide range of potential outcomes, as in the case of the groundwater pollution vulnerability study for the County of Copenhagen reported by Refsgaard et al. (2006) or the study of water-resources planning by Hughes et al. (2008). Estimates can still be considered in terms of some relative likelihood, but there may be little confidence in deciding between outcomes. One response to such a situation is to invest in trying to reduce the uncertainties. Another is to take an alternative approach to simple risk-based decision making, as has been advocated for the case of climate change impacts by Wilby and Dessai (2010) and Beven (2011), unless uncertainties can be reduced. Hence, acknowledgement of uncertainties opens up further research opportunities and, hopefully, stimulates development of novel methods to constrain them.

\section{()) We deepen academic understanding}

In this comment, we stress uncertainty estimation as part of a learning process, but does it have any bearing on the education of students? Understanding risk and uncertainty is of course important for the students to correctly interpret scientific results, but it can also have a positive effect on the deeper understanding of both hydrological processes and models used for predictions. High school students have been shown to appreciate that there can be multiple mathematical representations of a scientific phenomenon and that these can change when new knowledge becomes available (Treagust et al., 2002). Even so, from our own teaching experiences, we have found that students can take many views on hydrological models, from blind belief in the model outcome to full scepticism towards the outcome since 'it's just a model'. One hypothesis is that the more complex the models become, the more belief many students tend to put in the outcome, no matter the suitability of the model to its intended purpose. A lack of understanding of the limitations and capabilities of models can result in a naïve belief in model outputs as facts (deterministic outcomes). 
However, by clearly showing students the uncertainties involved in the modelling process, the teacher can aid the process of getting a balanced picture of models as hypotheses. In this way, overconfidence in model results, and if proven wrong, subsequent disappointment and perhaps distrust of models as a tool, can be avoided. One initiative in this direction is the educational model developed by AghaKouchak et al. (2012), which through a graphical interface enables ensemble streamflow simulations and sensitivity analysis to introduce students to the concepts of uncertainty and predictive power.

Hydrologists are working in a field which is becoming increasingly interdisciplinary and therefore requires better communication with non-hydrologists (Wagener et al., 2012). Students with proper training in uncertainty analysis will have a toolkit to scrutinise modelling efforts and thereby contribute to decision-making processes with substantiated claims of knowledge or lack thereof. They will be well prepared for situations where decision making will be based on assessments of risk of potential outcomes rather than traditional normbased probability assessments. Proper training of the new generation of hydrologists in uncertainty assessments and communication of risk will be an important part of their working skills and will most definitely have positive effects on their future careers.

\section{(-) Uncertainty estimation is getting easier}

Increases in computational power, parallel processes, and software mean that a wider range of models than ever before can be applied within an uncertainty estimation framework. There are still models (such as gridded, multiple layer, global earth systems science models) where run times are still too slow, but even such models are now being run on an ensemble basis for regional predictions (e.g. UKCP09) and even, for coarser grid scales at global scale (www.climateprediction.net). There is still scope for improved software in terms of both implementing different models and searching the model space for acceptable or high likelihood simulations more efficiently, but we can expect that more and more models will be subjected to uncertainty analyses. There are also improved and new observational techniques that provide better data to run and evaluate models, such as acoustic Doppler measurements of stream discharges, $\mathrm{X}$-band estimation of rainfall, eddy correlation estimates of evapotranspiration, and remote sensing imaging for different hydrologically relevant variables.

Scientists have much to gain from openly communicating current knowledge, modelling results, and the uncertainties involved. Pappenberger et al. (2012), aware of this importance, have recently conducted a study aiming at improving the communication of probabilistic flood forecasts and their associated uncertainty. The environmental virtual observatory (http://194.66.252.157/ evo/), founded by the UK National Environmental Research Council, is another initiative in this direction, making environmental data and modelling available for the global community at all levels. Although the project is still in an early phase, stakeholders and local communities are already involved in evaluation of tools developed for accessing catchment information, and the project has the potential of becoming a novel web service for sharing and investigating environmental data.

\section{The Future is Bright}

'Does it seem paradoxical to be positive (comfortable and confident) in the face of uncertainty (ambiguity and doubt)? Yes. But that is exactly what a [hydrologist ${ }^{1}$ will need in order to be a successful decision maker in the future.' (Gelatt, 1989)

The future is, we believe, bright for the incorporation of uncertainty estimation in hydrological modelling. More and more agencies are becoming aware that it is important to be open and transparent about decision making, and this will often involve being open, transparent, and honest about the uncertainties involved. An implicit advantage is that the analyst is then less likely to be wrong. We emphasise that uncertainty estimation should not be the end point of a project but should rather be part of a learning process about how to represent the hydrology in a particular place, including the cost-effective collection of additional information that will help constrain both epistemic and aleatory uncertainties. It should be expected that there will continue to be multiple hypotheses about how uncertainty estimation should be done. However, it is clear that uncertainty assessments can have important consequences for decision making, which in itself is sufficient reason to be positive about the process. However, here, we have elaborated seven additional reasons to be positive about uncertainty estimation in hydrological science and education - even on a rainy day.

\section{References}

AghaKouchak A, Nakhjiri N, Habib E. 2012. An educational model for ensemble streamflow simulation and uncertainty analysis. Hydrology and Earth System Sciences Discussions 9: 7297-7315.

Beven KJ. 2002. Towards an alternative blueprint for a physically based digitally simulatedhydrologic response modelling system. Hydrological Processes 16(2): 189-206.

Beven KJ. 2011. I believe in climate change but how precautionary do we need to be in planning for the future? Hydrological Processes 25: 1517-1520, DOI: 10.1002/hyp.7939.

$\overline{\text { original subject }}$ was 'person' 
Beven KJ. 2012. Causal models as multiple working hypotheses about environmental processes. Comptes Rendus Geoscience, Académie de Sciences, Paris. DOI: 10.1016/j.crte.2012.01.005.

Beven KJ, Binley AM. 1992. The future of distributed models: model calibration and uncertainty prediction. Hydrological Processes 6: 279-298.

Beven KJ, Westerberg I. 2011. On red herrings and real herrings: disinformation and information in hydrological inference. Hydrological Processes 25: 1676-1680, DOI: 10.1002/hyp.7963.

Beven KJ, Smith, PJ, Freer JE, 2008. So just why would a modeller choose to be incoherent. Journal of Hydrology 354: 15-32.

Beven KJ, Smith PJ, Wood A, 2011. On the colour and spin of epistemic error (and what we might do about it). Hydrology and Earth System Sciences 15: 3123-3133.

Birkel C, Tetzlaff D, Dunn SM, Soulsby C. 2010. Towards a simple dynamic process conceptualization in rainfall-runoff models using multi-criteria calibration and tracers in temperate, upland catchments. Hydrological Processes 24: 260-275.

Blazkova S, Beven KE. 2009. A limits of acceptability approach to model evaluation and uncertainty estimation in flood frequency estimation by continuous simulation: Skalka catchment, Czech Republic. Water Resources Research 45, DOI: 10.1029/ 2007WR006726.

Box GE. 1976. Science and statistics. Journal of the American Statistical Association 71(356): 791-799.

Brath A, Montanari A, Toth E. 2004. Analysis of the effects of different scenarios of historical data availability on the calibration of a spatially-distributed hydrological model. Journal of Hydrology 291(3-4): 232-253.

Brunner P, Doherty J, Simmons CT. 2012. Uncertainty assessment and implications for data acquisition in support of integrated hydrologic models. Water Resources Research 48: W07513, DOI: 10.1029/2011WR011342.

Bulygina N, McIntyre N, Wheater H. 2009. Conditioning rainfallrunoff model parameters for ungauged catchments and land management impacts analysis. Hydrology and Earth System Sciences 13(6): 893-904.

Chatfield C. 1995. Model uncertainty, data mining and statistical inference. Journal of the Royal Statistical Society Series A 158: 419-466.

Fenicia F, McDonnell JJ, Savenije HHG. 2008. Learning from model improvement: On the contribution of complimentary data to process understanding. Water Resources Research 44: W06419.

Frewer L, Hunt S, Brennan M, Kuznesof S, Ness M, Ritson C. 2003. The views of scientific experts on how the public conceptualize uncertainty. Journal of Risk Research 6(1): 75-85.

Gelatt HB. 1989. Positive uncertainty: a new decision-making framework for counceling. Journal of Counceling Psychology 36(2): 252-256.

Grayson RB, Moore ID, Mcmahon TA. 1992. Physically Based Hydrologic Modeling.2. Is the Concept Realistic. Water Resources Research 28(10): 2659-2666.

Hamilton AS, Moore RD. 2012. Quantifying Uncertainty in Streamflow Records. Canadian Water Resources Journal 37(1): 3-21.

Hughes DA, Sawunyama T, Kapangaziwiri E. 2008. Incorporating estimation uncertainty into water resource development planning in ungauged basins in southern Africa. In: Sustainable Hydrology for the 21st Century, Proc. 10th BHS National Hydrology Symposium, Exeter.

Jacob M, Hellström T. 2000. Policy understanding of science, public trust and the BSE-CJD crisis. Journal of Hazardous Materials 78: 303-317.

Juston J, Seibert J, Johansson, P-O. 2009. Temporal sampling strategies and uncertainty in calibrating a conceptual hydrological model for a small boreal catchment. Hydrological Processes 23: 3093-3109.

Juston JM, Andrèn O, Kätterer T, Jansson P-E. 2010. Uncertainty analyses for calibrating a soil carbon balance model to agricultural field trial data in Sweden and Kenya. Ecological Modelling 221: 1880-1888.

Kirchner JW. 2006. Getting the right answers for the right reasons: Linking measurements, analyses, and models to advance the science of hydrology. Water Resources Research 42(3): W03S04, DOI: 10.1029/ $2005 w r 004362$.

Klemeš V. 1986. Dilettantism in Hydrology - Transition or Destiny. Water Resources Research 22(9): 177S-188S.

Konz M, Seibert J. 2010. On the value of glacier mass balances for hydrological model calibration. Journal of Hydrology 385: 238-246, DOI: $10.1016 /$ j.jhydrol.2010.02.025.

Krueger T, Freer J, Quinton JN, Macleod CJA, Bilotta GS, Brazier RE, Butler P, Haygarth PM. 2010. Ensemble evaluation of hydrological model hypotheses. Water Resources Research 46: W07516, DOI: 10.1029/2009WR00784.

Lerat J, Andréassian V, Perrin C, Vaze J, Perraud JM, Ribstein P, Loumagne C. 2012. Do internal flow measurements improve the calibration of rainfall-runoff models? Water Resources Research 48, W02511, DOI: 10.1029/2010WR010179.

McMillan H, Freer J, Pappenberger F, Krueger T, Clark M. 2010. Impacts of uncertain river flow data on rainfall-runoff model calibration and discharge predictions. Hydrological Processes 24(10): 1270-1284.

McMillan H, Krueger K, Freer J. 2012. Benchmarking observational uncertainties for hydrology: Rainfall, river discharge and water quality. Hydrological Processes, DOI: 10.1002/hyp.9384.

Pappenberger F, Beven KJ. 2006. Ignorance is bliss: 7 reasons not to use uncertainty analysis. Water Resources Research 42: W05302, DOI: 10.1029/2005WR004820, 2006.

Pappenberger F, Stephens E, Thielen J, Salamon P, Demeritt D, van Andel SJ, Wetterhall F, Alfieri L. 2012. Visualising probabilistic flood forecast information: expert preferences and perceptions of best practice in uncertainty communication. Hydrological Processes DOI: 10.1002/hyp.9253.

Refsgaard JC, van der Sluijs JP, Brown J, van der Keur P. 2006. A framework for dealing with uncertainty due to model structure error. Advances in Water Resources 29: 1586-1597.

Reusser DE, Zehe E. 2011. Inferring model structural deficits by analyzing temporal dynamics of model performance and parameter sensititvity. Water Resources Research 47: W07550.

Roth D, Warner J. 2007. Flood risk, uncertainty and changing river protection policy in the Netherlands: the case of the 'calamity polders'. Tijdschrift voor Economische en Sociale Geografie 98(4): 519-525.

Seibert J. 2000. Multi-criteria calibration of a conceptual rainfallrunoff model using a genetic algorithm. Hydrology and Earth System Sciences 4(2): 215-224.

Seibert J, Beven KJ. 2009. Gauging the ungauged basin: how many discharge measurements are needed? Hydrology and Earth Science Systems 13: 883-892.

Seibert J, McDonnell JJ. 2002. On the dialog between experimentalist and modeler in catchment hydrology: Use of soft data for multicriteria model calibration. Water Resources Research 38(11): 1241.

Seibert J, McDonnell JJ. 2010. Land-cover impacts on streamflow: A change-detection modeling approach that incorporates parameter uncertainty. Hydrological Sciences Journal 55(3): 316-332.

Singh R, Wagener T, van Werkhoven K, Mann ME, Crane R. 2011. A trading-space-for-time approach to probabilistic continuous streamflow predictions in a changing climate - accounting for changing watershed behaviour. Hydrology and Earth System Sciences 15: 3591-3603.

Sivapalan M, Takeuchi K, Franks SW, Gupta VK, Karambiri H, Lakshmi V, Liang X, McDonnell JJ, Mendiondo EM, O'Connell PE, Oki T, Pomeroy JW, Schertzer D, Uhlenbrook S, Zehe E. 2003. IAHS decade on Predictions in Ungauged Basins (PUB), 2003-2012: Shaping an exciting future for the hydrological sciences. Hydrological Sciences Journal-Journal Des Sciences Hydrologiques 48(6): 857-880.

Stephens GL, Kummerow CD. 2007. The remote sensing of clouds and precipitation from space: A review. Journal of the Atmospheric Sciences 64(11): 3742-3765.

Thyer M, Renard B, Kavetski D, Kuczera G, Franks SW, Srikanthan S. 2009. Critical evaluation of parameter consistency and predictive uncertainty in hydrological modeling: A case study using Bayesian 


\section{J. M. JUSTON ET AL.}

total error analysis. Water Resources Research 45: W00b14, DOI: $10.1029 / 2008 w r 006825$.

Treagust DF, Chittleborough G, Mamiala TL. 2002. Students' understanding of the role of scientific models in learning science. International Journal of Science Education 24(4): 357-368.

Viney NR, Bates BC. 2004. It never rains on Sunday: The prevalence and implications of untagged multi-day rainfall accumulations in the Australian high quality data set. International Journal of Climatology 24 (9): 1171-1192.

Vrugt JA, Bouten W, Gupta HV, Sorooshian S. 2002. Toward improved identifiability of hydrologic model parameters: The information content of experimental data. Water Resources Research 38(12): 1312, DOI: 10.1029/2001WR001118, 2002.

Wagener T, Montanari A. 2011. Convergence of approaches toward reducing uncertainty in predictions in ungauged basins. Water Resources Research 47: W06301.

Wagener T, Kelleher C, Weiler M, McGlynn B, Gooseff M, Marshall L, Meixner T, McGuire K, Gregg S, Sharma P, Zappe S. 2012. It takes a community to raise a hydrologist: the Modular Curriculum for Hydrologic Advancement (MOCHA). Hydrology and Earth System Sciences Discussions 9: 2321-2356.
Wardekker JA, Van der Sluijs JP, Janssen PHM, Kloprogge P, Petersen AC. 2008. Uncertainty communication in environmenta assessments: views from the Dutch science-policy interface. Environmental Science \& Policy 11: 627-641.

Westerberg IK, Walther A, Guerrero J-L, Coello Z, Halldin S, Xu CY, Chen D, Lundin L-C. 2010. Precipitation data in a mountainous catchment in Honduras: quality assessment and spatiotemporal characteristics. Journal of Theoretical and Applied Climatology 101: 381-396.

Westerberg IK, Guerrero J-L, Younger PM, Beven KJ, Seibert J, Halldin S, Freer JE, Xu C-Y. 2011. Calibration of hydrologic models using flowduration curves. Hydrology and Earth System Sciences 7: 9467-9522.

Wilby R, Dessai S. 2010. Robust adaptation to climate change. Weather 65: 180-185.

Winsemius HC, Schaefli B, Montanari A, Savenije HHG. 2009. On the calibration of hydrological models in ungauged basins: A framework for integrating hard and soft hydrological information. Water Resources Research 45: W12422, DOI: 10.1029/2009wr007706.

Yadav M, Wagener T, Gupta H. 2007. Regionalization of constraints on expected watershed response behavior for improved predictions in ungauged basins. Advances in Water Resources 30(8): 1756-1774. 